\title{
Experimental Investigation on the LCF Behavior Affected by Manufacturing Defects and Creep Damage of One Selective Laser Melting Nickel-Based Superalloy at $815^{\circ} \mathrm{C}$
}

\author{
Xiao-An Hu ${ }^{1,2} \cdot$ Gao-Le Zhao ${ }^{1,2} \cdot$ Yun Jiang ${ }^{1,2} \cdot$ Xian-Feng Ma ${ }^{3} \cdot$ Fen-Cheng Liu ${ }^{4}$ Jia Huang ${ }^{5} \cdot$ Cheng-Li Dong $^{6}$
}

Received: 11 September 2019 / Revised: 22 October 2019 / Published online: 23 December 2019

(C) The Chinese Society for Metals (CSM) and Springer-Verlag GmbH Germany, part of Springer Nature 2019

\begin{abstract}
Uniaxial tensile tests and stress-controlled low-cycle fatigue (LCF) and creep-fatigue interaction (CFI) tests of Inconel 625 alloy manufactured by selective laser melting (SLM) were performed at $815^{\circ} \mathrm{C}$ in air environments. The microstructure was characterized by optical microscopy and scanning electron microscopy after testing. The results confirmed that significant embrittlement and large scatter in LCF life are resulted from manufacturing defects. The CFI life is decreased sharply to approximately dozens of cycles with the accumulated creep strain; however, the selected dwell time (i.e., $60 \mathrm{~s}$ and $300 \mathrm{~s}$ ) exhibits low sensitivity to the fracture time and elongation to failure. The embrittlement of SLM Inconel 625 was proposed to be due to the low grain uniformity and precipitation of carbides at the grain boundaries. Due to the quality of the SLM process, the accelerated initiation and propagation of fatigue crack are caused by the present unmelted powder particles, which result in the large dispersion of LCF life. Meanwhile, due to the accumulation of creep damage, cracks in the CFI test are initiated along the grain boundaries and then linked together, contributing to a significant decline in fatigue life.
\end{abstract}

Keywords Selective laser melting $\cdot$ Low-cycle fatigue $\cdot$ Creep-fatigue interaction $\cdot$ Failure analysis

\section{Introduction}

Available online at http://link.springer.com/journal/40195.

Jia Huang

huangjia216@126.com

1 School of Aircraft Engineering, Nanchang Hangkong University, Nanchang 330063, China

2 Jiangxi Key Laboratory of Micro Aeroengine Technology, Nanchang 330063, China

3 Sino-French Institute of Nuclear Engineering and Technology, Sun Yat-Sen University, Zhuhai 519082, China

4 National Defence Key Discipline Laboratory of Light Alloy Processing Science and Technology, Nanchang 330063, China

5 School of Aeronautics and Astronautics, Central South University, Changsha 410083, China

6 Materials Evaluation Center for Aeronautical and Aeroengine Application, AECC Beijing Institute of Aeronautical Materials, Beijing 100095, China

Additive manufacturing (AM) technology of metals has shown great potential for the production of complex and netshaped components [1-3]. Selective laser melting (SLM), as one of the most promising AM processing technologies of nickel-based alloys, has attracted extensive attention in aerospace, automotive and nuclear industries due to its unique technical advantages [4-6]. However, in comparison with the traditional forged and cast superalloys, a high level of residual stress, as well as inhomogeneous microstructures and phase distributions, exists in the as-built SLM superalloys, and defects also inevitably arise in the manufacturing process [7-9].

As far as the nickel-based superalloys mainly used in high-temperature environments are concerned, both lowcycle fatigue (LCF) and creep-fatigue interaction (CFI) are the dominant damage modes for turbine disks and turbine blades [10-13]. Hence, no matter which material manufacturing method is used for nickel-based superalloys, thorough investigations on mechanical properties, LCF and CFI should be emphasized in real applications. The tensile properties and related failure mechanisms of the SLM 
superalloys have been investigated [14-16]. Koutiri et al. [17] studied the influence of the related process parameters on the fatigue properties of SLM Inconel 625 parts. The test results indicated that the polished and the as-built specimens exhibited similar fatigue resistance, leading to the conclusion that the defects related to crack initiation for both of the as-built and polished samples were similar in size. The proposed fatigue crack initiation mechanism involved the particles embedded on the surface, porosity located on the surface or subsurface and local plasticity. Saarimäki et al. [18] reported that a longer dwell time accelerated the crack propagation of additive manufactured Hastelloy $\mathrm{X}$ at $700{ }^{\circ} \mathrm{C}$. Konečná et al. [19] showed that SLM Inconel 718 was less resistant to the growth of long cracks in the near-threshold region than the alloys manufactured by conventional process. They attributed this difference to the low content of boron, residual stresses and finer microstructure associated with the SLM process. Prithivirajan and Sangid [20] developed a crystal plasticity model to capture the effect of defects on the fatigue crack initiation of AM Inconel 718. Moreover, they proposed damage indicator parameters to determine the location of crack initiation. Yamashita et al. [21] indicated that the particular effects of defects present near the surface must be carefully considered to improve the fatigue design of AM In718. Xu et al. [22] showed that the orientation effect on the fatigue behavior of SLM K536 could be neglected at high temperature (i.e., $600{ }^{\circ} \mathrm{C}$ ). Aydinöz et al. [23] concluded that microstructure evolution was the key parameter for LCF lives after the minimization of porosity by HIP for SLM In718. The elimination of submicron cell structures led to increased hysteresis width and energy dissipation per cycle, contributing to shorter fatigue lives. Kirka et al. [24] found that different textures produced by electron beam melting have a decisive influence on the LCF behavior of Inconel 718 at room temperature. The above research reports indicated that the fatigue behavior and failure mechanism were controlled or influenced by various parameters, including quality of the powder, printing process and post-treatments. However, as a result of these complex and multiple parameter-related processes, few studies have been carried out systematically on the LCF performance and failure mechanism of SLM Ni-based superalloys at high temperatures.

Inconel 625, one of the most widely used Ni-base superalloys produced by the SLM process, is a solid solutionstrengthened superalloy [25]. It commonly works at elevated temperatures of $800-900{ }^{\circ} \mathrm{C}$, i.e., in casing and guide vane of aeroengines. As a critical component of an aeroengine experiences significant tensile, fatigue and creep stresses due to centrifugal loading and thermal loading induced by the temperature gradient at elevated temperature. Although the fatigue properties of AM Inconel 625 have been extensively investigated and discussed in the last decade, only few works focused on the aeroengine service temperature environment. In order to promote the application of this material in the aerospace field with high reliability, undoubtedly, it is of great significance in superalloy AM field to understand the formation mechanism of casting defects (i.e., quality of the powder, printing process and post-treatments) and control them to an extremely low level. However, the cast defects via AM processing cannot be fully removed in superalloys; hence, the influence of the number, size distribution and position information of defects on mechanical properties and LCF behaviors should be fully evaluated at elevated temperatures [26, 27]. In the present work, tensile tests and stresscontrolled LCF and CFI tests were performed at $815^{\circ} \mathrm{C}$. The fatigue behaviors under different load values and dwell time were considered. Through microstructure analysis, the crack initiation mechanism and fracture analysis were examined and discussed.

\section{Experimental}

\subsection{Powder}

In the present work, gas-atomized spherical powder material of Inconel 625 was provided by Xi' an Bright Laser Technologies Co., Ltd., and was used for manufacturing the SLM samples. As can be seen in Fig. 1, the powder particle with an average particle size of around $12 \mu \mathrm{m}$ exhibits a log-normal distribution and the particle size distribution is between 5 and $40 \mu \mathrm{m}$. The morphology of powder was observed by SEM using SU1510 and Nova Nano SEM450 at Nanchang Hangkong University. The powders are consisted of fairly spherical particles with some clusters as shown in Fig. 2a. Some dendrites can be observed in Fig. 2b. The chemical

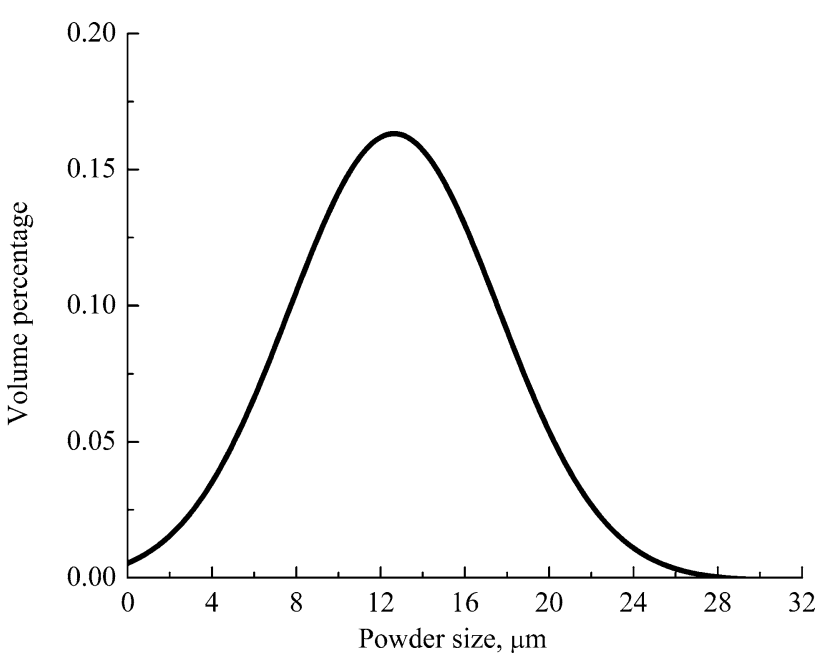

Fig. 1 Powder size distribution 
composition (provided by Xi' an Bright Laser Technologies Co., Ltd.) of the Inconel 625 spherical powder used in fatigue research is presented in Table 1.

\subsection{Material and Specimen Preparation}

The building direction was parallel to the axis of the specimen. The layer thickness, beam diameter and laser power were $0.04 \mathrm{~mm}, 0.1 \mathrm{~mm}$ and $1 \mathrm{~kW}$, respectively. The as-built specimens were fabricated by a laser powder bed fusion system (BLT-S300) with a margin of $0.5 \mathrm{~mm}$ in each direction based on the dimensions as shown in Fig. 3. In order to release the residual stress and homogenize the material microstructure, a solution annealing heat treatment of the as-built specimens was performed in an argon environment. All the samples were heated up to the $1100{ }^{\circ} \mathrm{C}$ within $2 \mathrm{~h}$ at a constant heating rate and held for $1 \mathrm{~h}$, followed by furnace cooling to room temperature. Subsequently, the specimens were machined to the final size as specified in Fig. 3 with a surface roughness of $0.4 \mu \mathrm{m}$.

Figure 4 shows the microstructure of the samples in three mutually perpendicular planes before the testing. A very
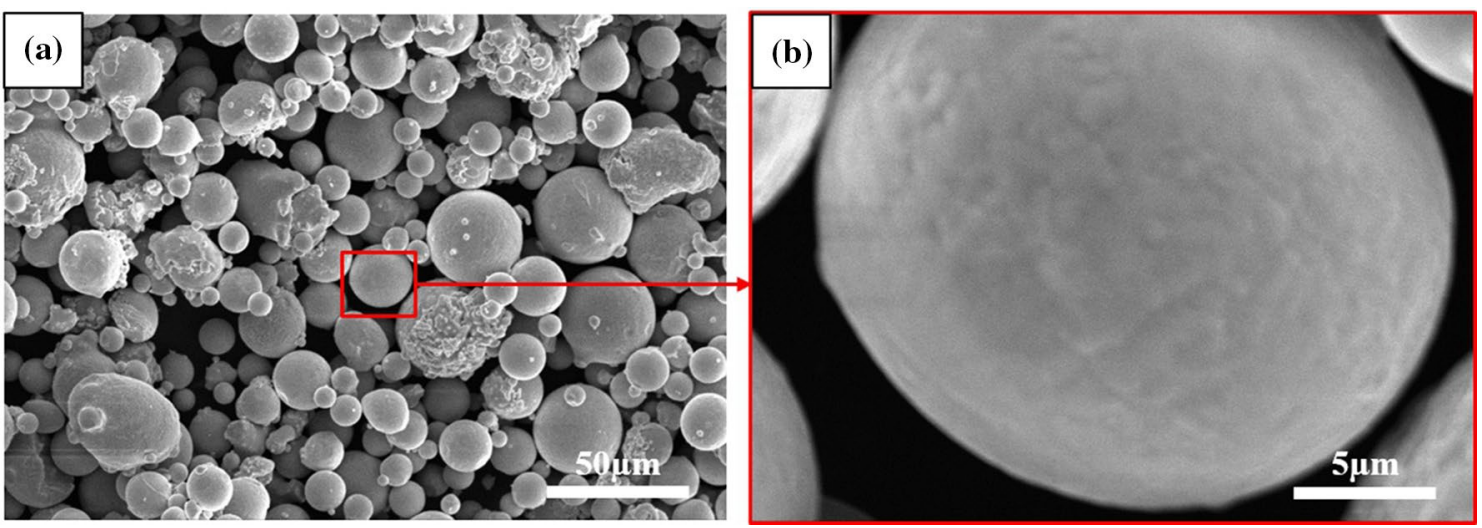

Fig. 2 Powder of Inconel 625: a shape of powder, $\mathbf{b}$ detail of granule shape

Table 1 Chemical compositions of Inconel 625 powder (wt\%)

\begin{tabular}{llllllll}
\hline $\mathrm{Al}$ & $\mathrm{C}$ & $\mathrm{Cr}$ & $\mathrm{Ti}$ & $\mathrm{Mo}$ & $\mathrm{Mn}$ & $\mathrm{Si}$ & \\
\hline 0.15 & 0.044 & 21.48 & 0.08 & 8.58 & $<0.01$ & 0.08 & 3.66 \\
\hline $\mathrm{Fe}$ & $\mathrm{Cu}$ & $\mathrm{Co}$ & $\mathrm{Mg}$ & $\mathrm{S}$ & $\mathrm{P}$ & $\mathrm{Ta}$ & $\mathrm{Ni}$ \\
\hline 4.77 & $<0.01$ & 0.02 & $<0.002$ & 0.014 & 0.005 & 0.04 & $\mathrm{Bal}$. \\
\hline
\end{tabular}

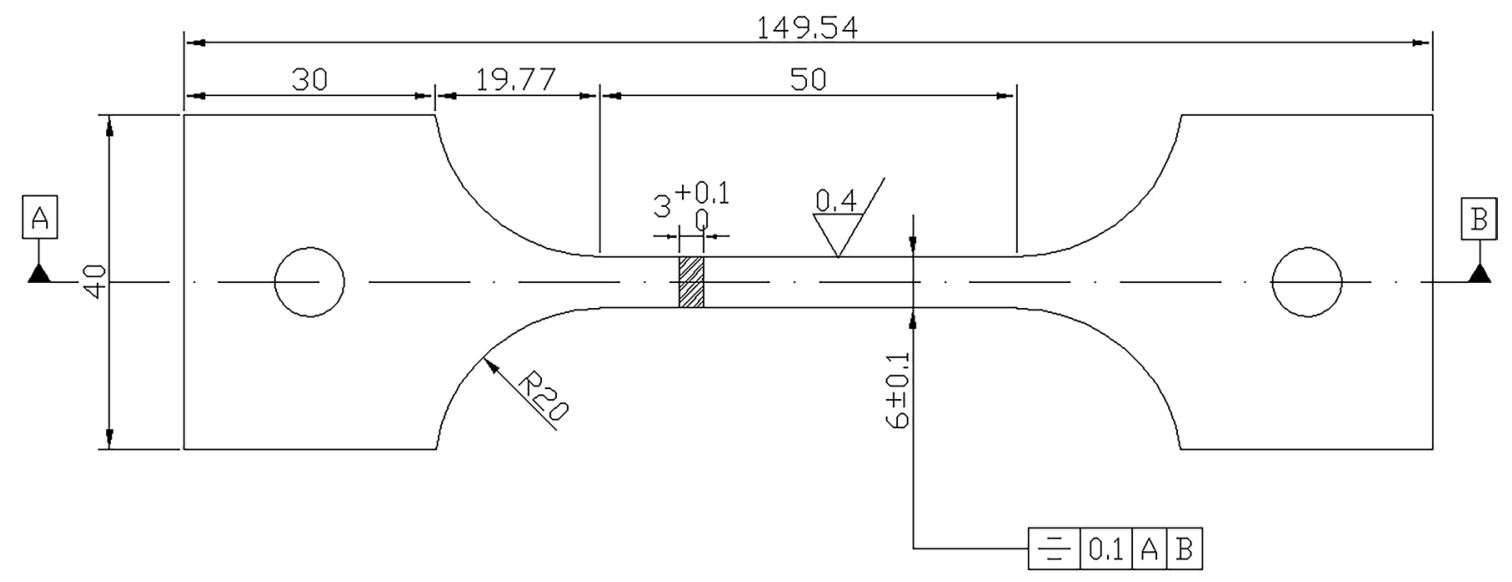

Fig. 3 Dimension of the tested samples (unit: $\mathrm{mm}$ ) 

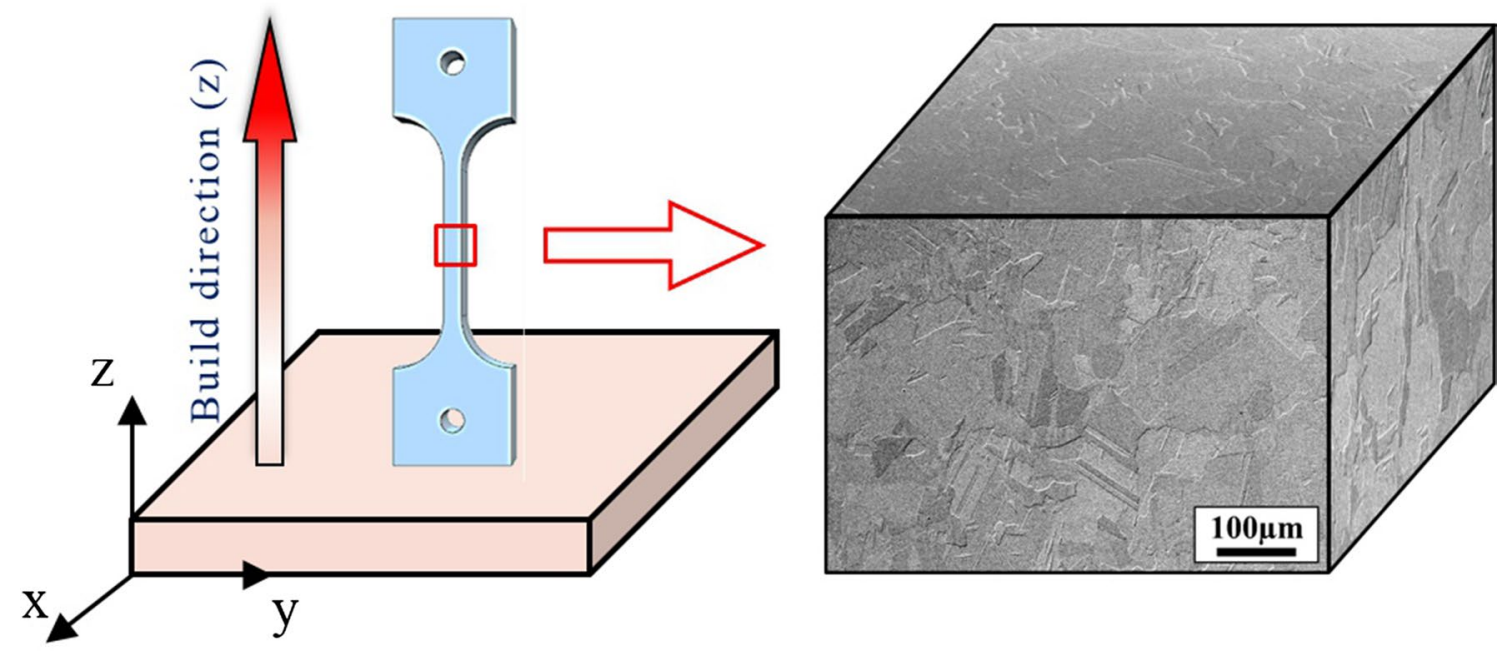

Fig. 4 Microstructure of SLM Inconel 625 in three mutually perpendicular planes before testing

clear morphology was identified, and the microstructure of the SLM-fabricated specimen was austenite. In addition, it was found that the size of the primary grains was not uniform and the twins were uniformly distributed. The formation of annealing twins provides an evidence that a high level of residual stress in the as-SLM sample is partially released during the post-annealing at $1100{ }^{\circ} \mathrm{C}$. However, the adjacent melting tracks were not observed. The development of this morphology can be attributed to the heat treatment process.

\subsection{Tensile and Fatigue Testing Procedure}

The casing and guide vane of the aeroengine are commonly operated at a high temperature of $800-900{ }^{\circ} \mathrm{C}$. Moreover, they are being subjected to a large load, i.e., fatigue, creep and fatigue and creep interaction. In order to simulate the engine service environment as much as possible, the testing of tensile strength and stress-controlled LCF and CFI was performed at $815{ }^{\circ} \mathrm{C}$ under a stress ratio of 0.1 on the Instron 8801 fatigue testing system.
The specimens were heated to the experimental temperature at a rating of $1{ }^{\circ} \mathrm{C} / \mathrm{s}$ using infrared radiant heating equipment for Instron 8801 and maintained for $15 \mathrm{~min}$ at this temperature before testing. Uniformity of the thermal field and temperature gradient control and monitor were ensured via three K-type thermocouples placed in the furnace. The strain history of the tested specimens was recorded using the high-temperature extensometer. Before the fatigue tests, the monotonic tensile testing of specimen $\mathrm{T}_{1}$ and specimen $\mathrm{T}_{2}$ was conducted. The frequency of the LCF was $10 \mathrm{~Hz}$, and the loading and unloading time of CFI was $1 \mathrm{~s}$. Dwell time of $1 \mathrm{~min}$ and $5 \mathrm{~min}$ was applied at the maximum stress for CFI tests. The LCF and CFI test matrix is listed in Table 2.
Table 2 LCF and CFI test matrix of SLM Inconel 625 at $815^{\circ} \mathrm{C}$

\begin{tabular}{lllccr}
\hline Specimen & Stress ratio & $\sigma_{\max }(\mathrm{MPa})$ & Dwell time $(\mathrm{s})$ & Fracture time $(\mathrm{s})$ & Cycle life \\
\hline $\mathrm{A}_{1}$ & 0.1 & 200 & 0 & 44,641 & 446,413 \\
$\mathrm{~A}_{2}$ & 0.1 & 200 & 0 & 21,350 & 213,495 \\
$\mathrm{~A}_{3}$ & 0.1 & 200 & 0 & 447 & 4471 \\
$\mathrm{~B}_{1}$ & 0.1 & 250 & 0 & 6667 & 66,671 \\
$\mathrm{~B}_{2}$ & 0.1 & 250 & 0 & 7689 & 76,894 \\
$\mathrm{C}_{1}$ & 0.1 & 300 & 0 & 261 & 261 \\
$\mathrm{C}_{2}$ & 0.1 & 300 & 0 & 1170 & 1170 \\
$\mathrm{D}_{1}$ & 0.1 & 200 & 60 & 6872 & 110 \\
$\mathrm{D}_{2}$ & 0.1 & 200 & 300 & 6146 & 20 \\
$\mathrm{D}_{3}$ & 0.1 & 250 & 60 & 1445 & 25 \\
\hline
\end{tabular}




\section{Monotonic Tensile Properties and LCF Behavior}

\subsection{Monotonic Tensile Properties}

As shown in Fig. 5, the engineering stress and strain curves of the two specimens $T_{1}$ and $T_{2}$ in the vertical direction were tested at $815^{\circ} \mathrm{C}$. This material exhibited pronounced hardening behavior, and the plastic was deformed in the same fashion as the traditional materials. A small dispersion existed between the two tensile curves, and specimen $T_{1}$ showed a slightly greater ultimate stress and a slightly smaller elongation. The average values of yield stress $(0.2 \%$ plastic strain) and ultimate stress of the alloy at $815^{\circ} \mathrm{C}$ were approximately $240 \mathrm{MPa}$ and $320 \mathrm{MPa}$, respectively.

For most of the metals manufactured by the traditional procedures, the ductility increases at higher temperatures. Figure 6 illustrates the comparison of elongation between Inconel 625 manufactured by SLM and forged material of the same composition at $815{ }^{\circ} \mathrm{C}[28]$ and reveals a significant discrepancy. The elongation rate of the forged Inconel 625 remains above $30 \%$ from room temperature up to $870{ }^{\circ} \mathrm{C}$ and even reaches a value as high as $96 \%$ at $815^{\circ} \mathrm{C}$. Meanwhile, the elongation rates of specimens $\mathrm{T}_{1}$ and $\mathrm{T}_{2}$ only reached $10 \%$, indicating poor ductility.

\subsection{Cyclic Deformation and Fatigue Life}

Figure 7 shows the typical stress and strain hysteresis loops measured during LCF and CFI procedures. As shown in Fig. 7a, an apparent ratcheting behavior was observed in specimen $\mathrm{C}_{2}$ under a high stress level (300 MPa) over the yield stress (240 MPa). It should be noted that the elongation rate after the fatigue fracture was about $18 \%$, which was significantly greater than that after the tensile fracture. Meanwhile, as shown in Fig. 7b, the strain accumulated to a greater extent in the dwell interval than in the stress fluctuation interval. The creep strain accumulation in one cycle was far greater than the plastic strain produced by LCF damage, eventually leading to a significant lifetime reduction under $\mathrm{CFI}$ loading. However, the elongation rate after $\mathrm{CFI}$ fracture was around $11 \%$, which was similar to that after the tensile fracture.

The LCF and CFI lives under various loading conditions are obtained as listed in Table 2. It revealed that the cyclic life decreases exponentially with the increase in cyclic stress range in both the LCF and CFI tests. A large scatter of LCF life was observed in the specimens with the maximum stress of $200 \mathrm{MPa}$. One specimen (specimen $\mathrm{A}_{3}$ ) failed with an extremely short life, which was substantially shorter than the average LCF life $(329,954$ cycles) of the other two samples $\left(A_{1}\right.$ and $\left.A_{2}\right)$. The $C F I$ life decreased significantly in comparison with the pure LCF life under the corresponding loads. The fatigue lives of specimen $\mathrm{D}_{1}\left(\sigma_{\max }=200 \mathrm{MPa}\right)$ and specimen $\mathrm{D}_{3}\left(\sigma_{\max }=250 \mathrm{MPa}\right)$ were reduced approximately

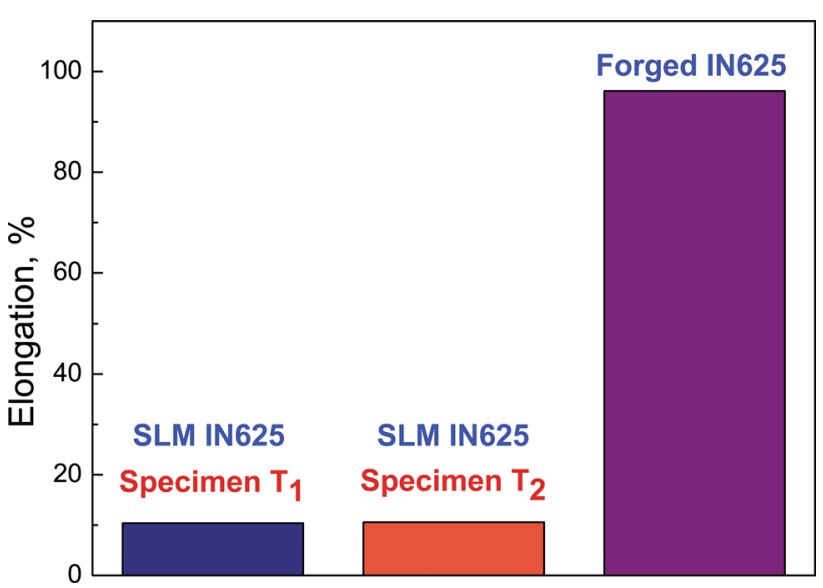

Fig. 6 Comparison of elongation in forged [28] and SLM Inconel 625 after fracture at $815^{\circ} \mathrm{C}$
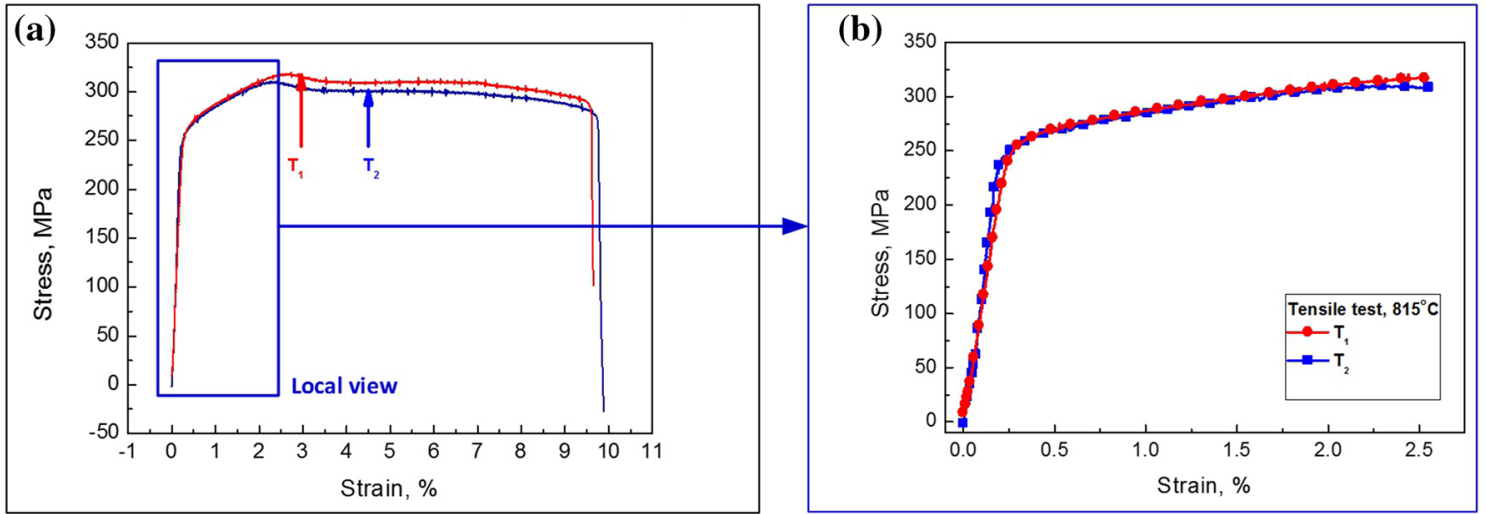

Fig. 5 Engineering stress and strain curves at $815^{\circ} \mathrm{C}$ for SLM Inconel 625: a global view, b local view 

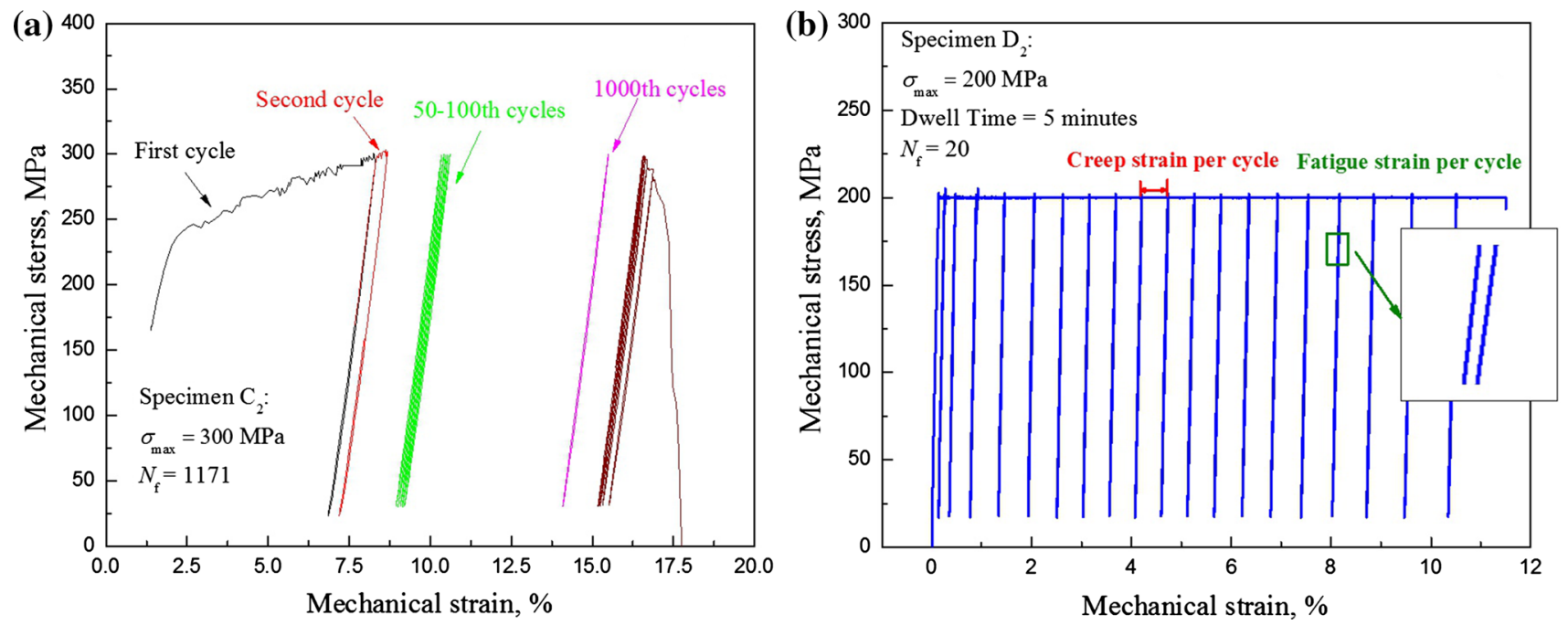

Fig. 7 Stress and strain relationship under LCF and CFI. a Pure LCF (specimen $\left.\mathrm{C}_{2}\right), \mathbf{b}$ CFI (specimen $\mathrm{D}_{2}$ )

2500 times due to the 1-min dwell time. When the dwell time increased from 60 to $300 \mathrm{~s}$, the cycles to failure of the specimen $\left(D_{2}\right)$ with a maximum stress of $200 \mathrm{MPa}$ further decreased. The test results indicated that the fracture time of specimens $D_{1}$ and $D_{3}$ was almost the same. Hence, the dwell time under the peak stress exhibited little effect on the fracture time of the creep-fatigue specimens. Since the maximum stress was identical, the failure process was dominated by the time-dependent deformation mechanism.

\section{Failure Analysis and Discussion}

\subsection{Tensile Failure Mechanism}

Both OM and SEM methods were used to analyze the microstructures in the longitudinal surface of the specimens after uniaxial tensile testing. Figure 8 demonstrates the fracture surfaces of the tensile specimen $T_{1}$ tested at $815^{\circ} \mathrm{C}$. No obvious plastic deformation was found to occur on the microstructure level. The intergranular cracks grew along the grain boundaries, and the cleavage features indicated obvious brittle fracture mode. Additionally, a number of printed marks with non-homogenous features could be clearly observed on the fracture surface.

Figure 9 illustrates the microstructure of the surface near the fracture section, where a great number of intergranular cracks were observed. Due to the non-homogenous grain distributions, inconsistent deformations occurred among the grains, resulting in grain boundary cracking and poor ductility of the superalloy. Meanwhile, the grains after the testing (Fig. 9) were almost identical to the undeformed grains before the testing (Fig. 4). As shown in Fig. 10, additional SEM analysis was conducted on the fractured specimens after tensile testing, and the microcracks were found on the grain boundaries, especially among the triple intersections. Since the orientations among the adjacent grains were different, the elastic and plastic properties were not the same. In order to satisfy the compatibility equation of deformation before the crack initiation, large stresses were developed in these locations, resulting in microcracks of $1-2 \mu \mathrm{m}$ in length. After the microcracks were initiated along the grain boundaries, the adjacent cracks were linked together to form relatively larger cracks, and the bearing area of the specimens deteriorated to failure.

\subsection{Failure Mechanism of LCF}

The failure mechanisms of SLM Inconel 625 subjected to LCF and CFI were investigated using SEM. Figure 11 illustrates the fracture surface of specimen $\mathrm{A}_{1}$. Three different zones including the crack initiation zone, the crack propagation zone and the final fracture zone are clearly observed in Fig. 11a. Typical river-like features (Fig. 11b) in the fatigue crack initiation zone originated from the lower right corner. The failure process was identical with that of the conventional metals, and the fatigue life was the longest among the three specimens. The fracture morphology of specimen $\mathrm{A}_{2}$ is shown in Fig. 12. Different from Fig. 11, several crack initiation sites in Fig. 12a were found either on the surface or subsurface. As shown in Fig. 12b, the defects characterized by incompletely melted powder particles in the subsurface were critical positions of the fatigue crack. The defects were located about 100-200 $\mu \mathrm{m}$ below the surface. The defects were similar to those found in other types of SLM materials, i.e., Ti-6Al-4V [29-31]. Formation of the defects can be attributed to the insufficient energy for fusing the powders in the new layers. River-like features were centered on the 

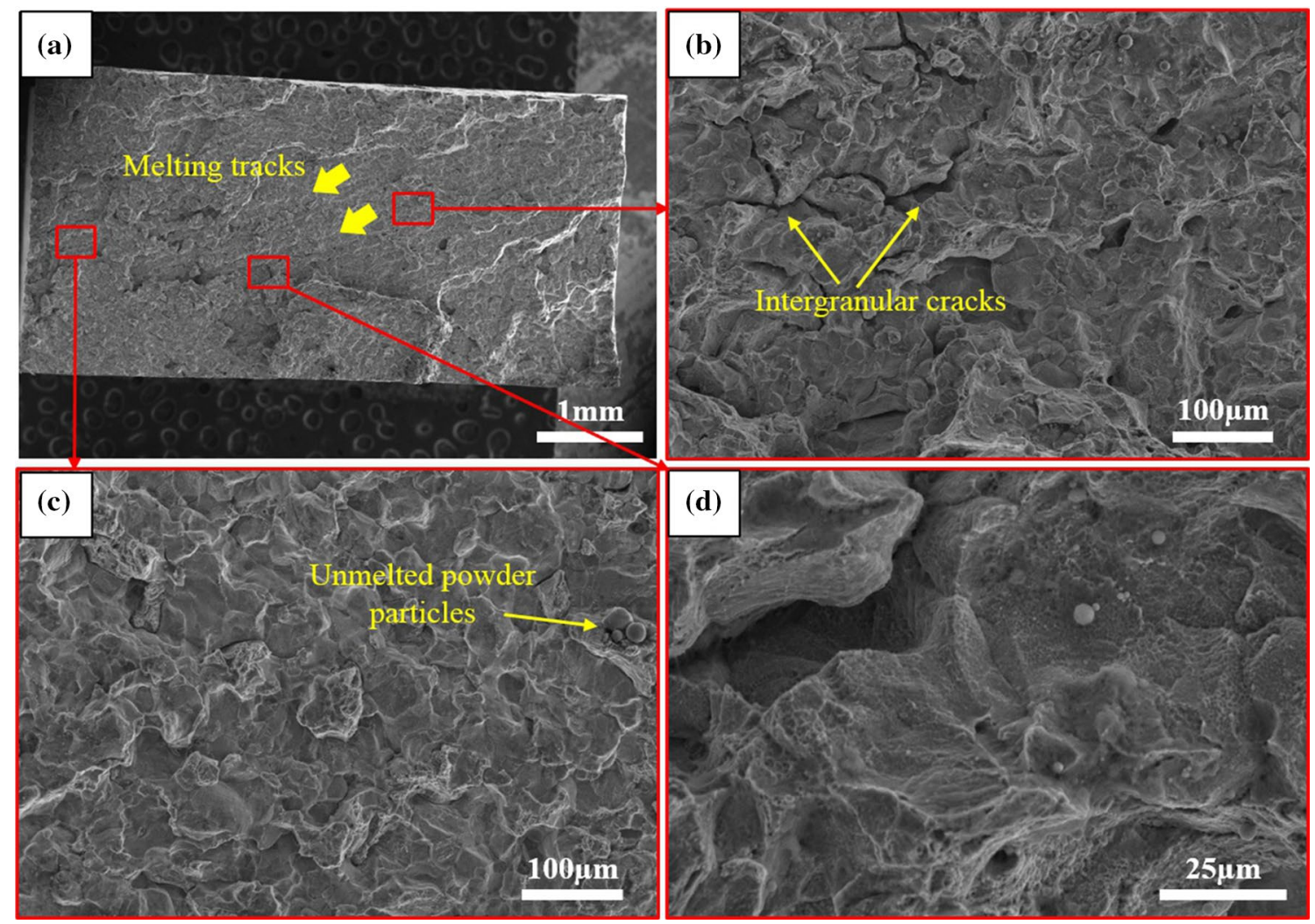

Fig. 8 Fracture surfaces of specimen $\mathrm{T}_{1}$ at $815^{\circ} \mathrm{C}$
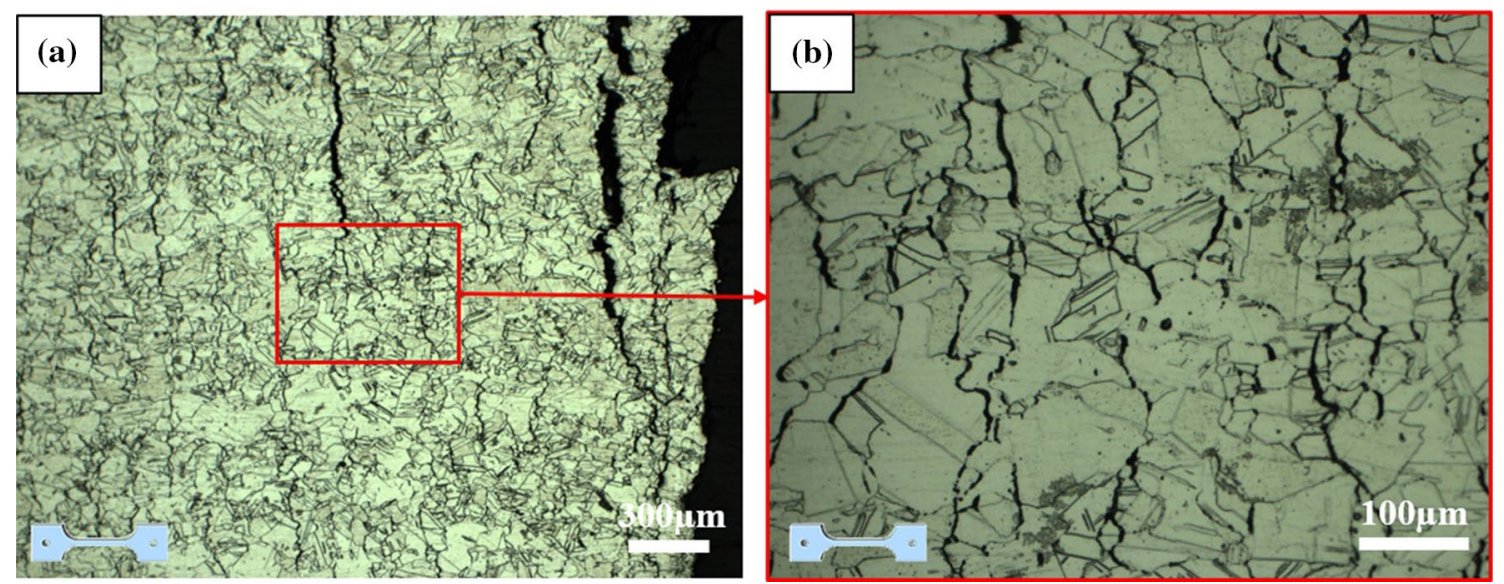

Fig. 9 Microstructures of the surface near the fracture section at $815^{\circ} \mathrm{C}$

defects as shown in Fig. 12b. Additionally, secondary cracks as well as striations can be observed in the crack propagation zone as shown in Fig. 12c. The fatigue striation in location B (Fig. 12d) was very close to the final fracture and was about $1-2 \mu \mathrm{m}$, indicating an exceptionally high fatigue crack growth rate, i.e., $1-2 \mathrm{E}-3 \mathrm{~mm} /$ cycle. Ultimately, although the applied loadings were the same, the life of this specimen was half the life of specimen $A_{1}$.
Figure 13 presents the fracture surface of specimen $A_{3}$, which was subjected to the maximum stress of $200 \mathrm{MPa}$ and exhibited the shortest life. Although the cycles to failure were 4471, no clear fatigue source is identified in Fig. 13a. The powder retained its original circular shape in Fig. $13 \mathrm{~b}$ due to the laser processing condition. Some circular pores (see Fig. 13c) were also observed, and the fractures of unmelted powder particles were present in the 

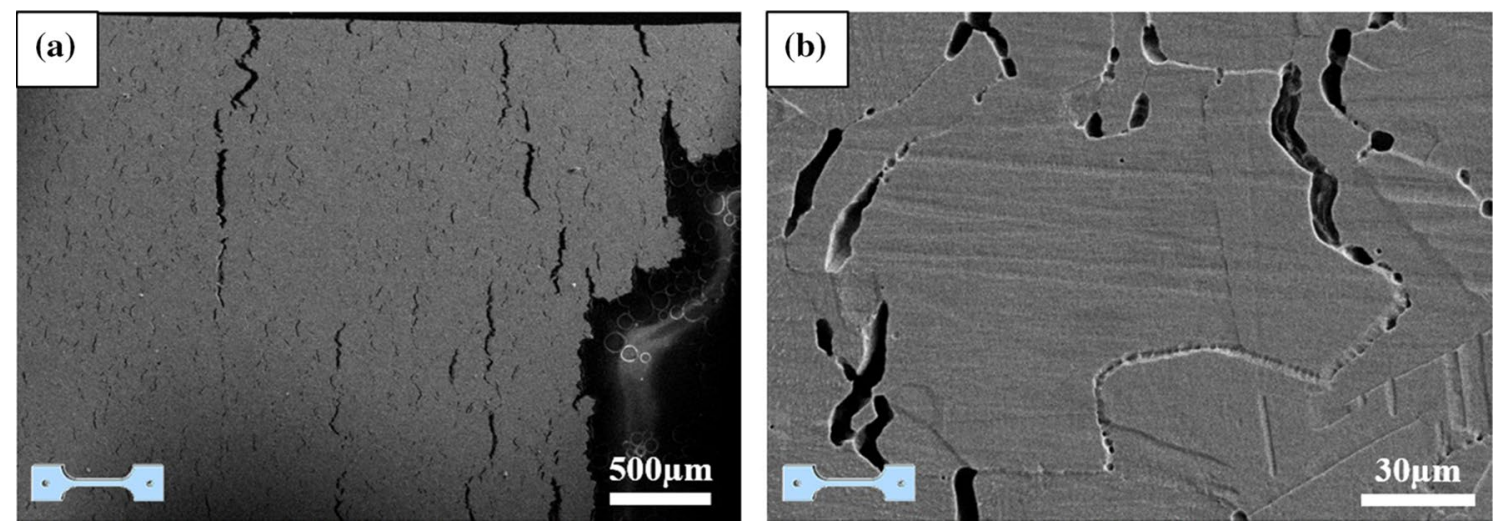

Fig. 10 Microstructures of specimens after tensile testing at $815^{\circ} \mathrm{C}$

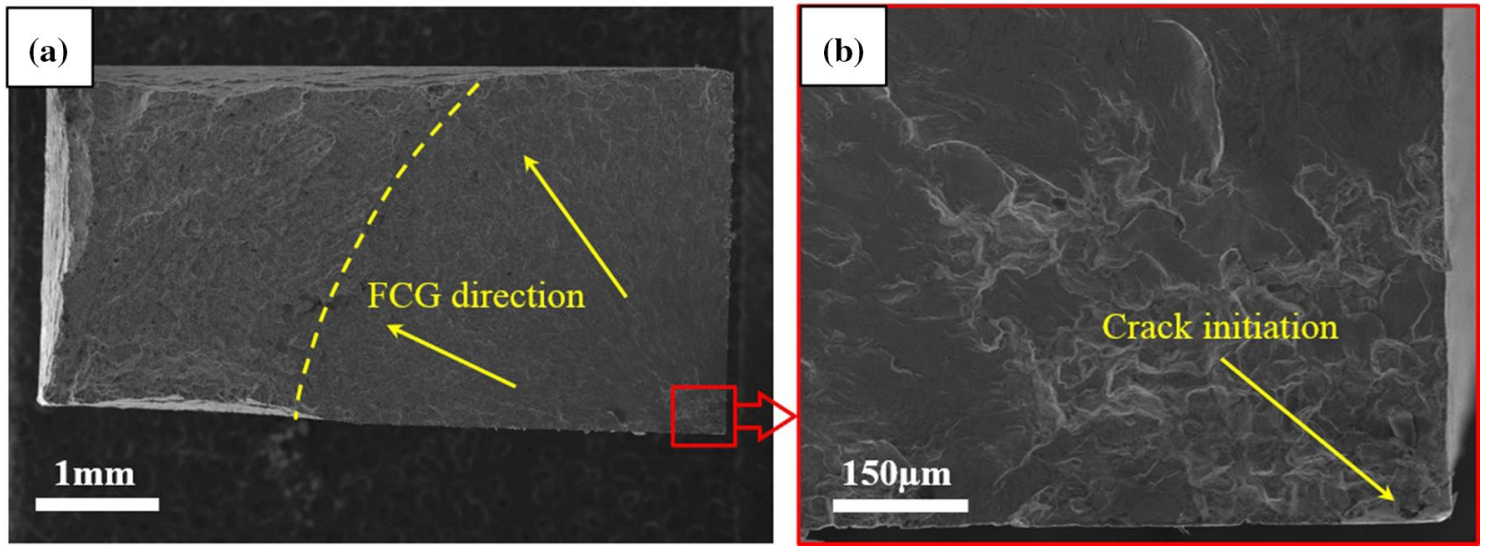

Fig. 11 Fracture surfaces of fatigue specimen $\mathrm{A}_{1}: \sigma_{\max }=200 \mathrm{MPa}, N_{\mathrm{f}}=446,413$

opposite fracture surface. The temperatures in the current and subsequent layers were estimated to be below the melting point of the powders, possibly due to the instability in voltage and other parameters. Meanwhile, the size of the powder particle observed in Fig. 13b, d was $82.8 \mu \mathrm{m}$, which exceeded the range with a mean size of $12 \mu \mathrm{m}$ (Fig. 1). The complete melting of this large powder particle requires additional laser energy and results in large defects that reduce the fatigue resistance of the alloy. Additionally, there are smaller unmelted powder particles surrounded by river-like features in Fig. 13c.

\subsection{Failure Mechanism of CFI}

The fracture surface of specimen $\mathrm{D}_{1}$ under $\sigma_{\max }=200 \mathrm{MPa}$ with 1-min hold time is shown in Fig. 14. Necking features are clearly visible in the top, right and lower right portions of the specimen in Fig. 14a, indicating the locations of the final fractures. Thus, the surface features of the remaining parts of the sample can be deduced, and the fatigue-creep cracks were generated before the final fracture. However, there was no obvious fatigue initiation site. Several crack fronts corresponding to the fatigue crack trace can be seen separated by hundreds of microns, indicating a large fatigue crack growth rate under CFI loading. The failure was in an intergranular manner with secondary cracks as illustrated in Fig. 14b. In the high magnification image in Fig. 14c, typical dimples indicated the evolution of the creep damage. The more detailed image in Fig. 14d shows a large amount of small net-like features in the grain boundaries, possibly related to creep deformation in the fracture surface.

\subsection{Discussion}

\subsubsection{Embrittlement at Elevated Temperatures}

The embrittlement commonly found in SLM superalloys at elevated temperatures was also observed in this work. The temperature dependence of yield strength and ultimate strength of the tested specimens manufactured by 

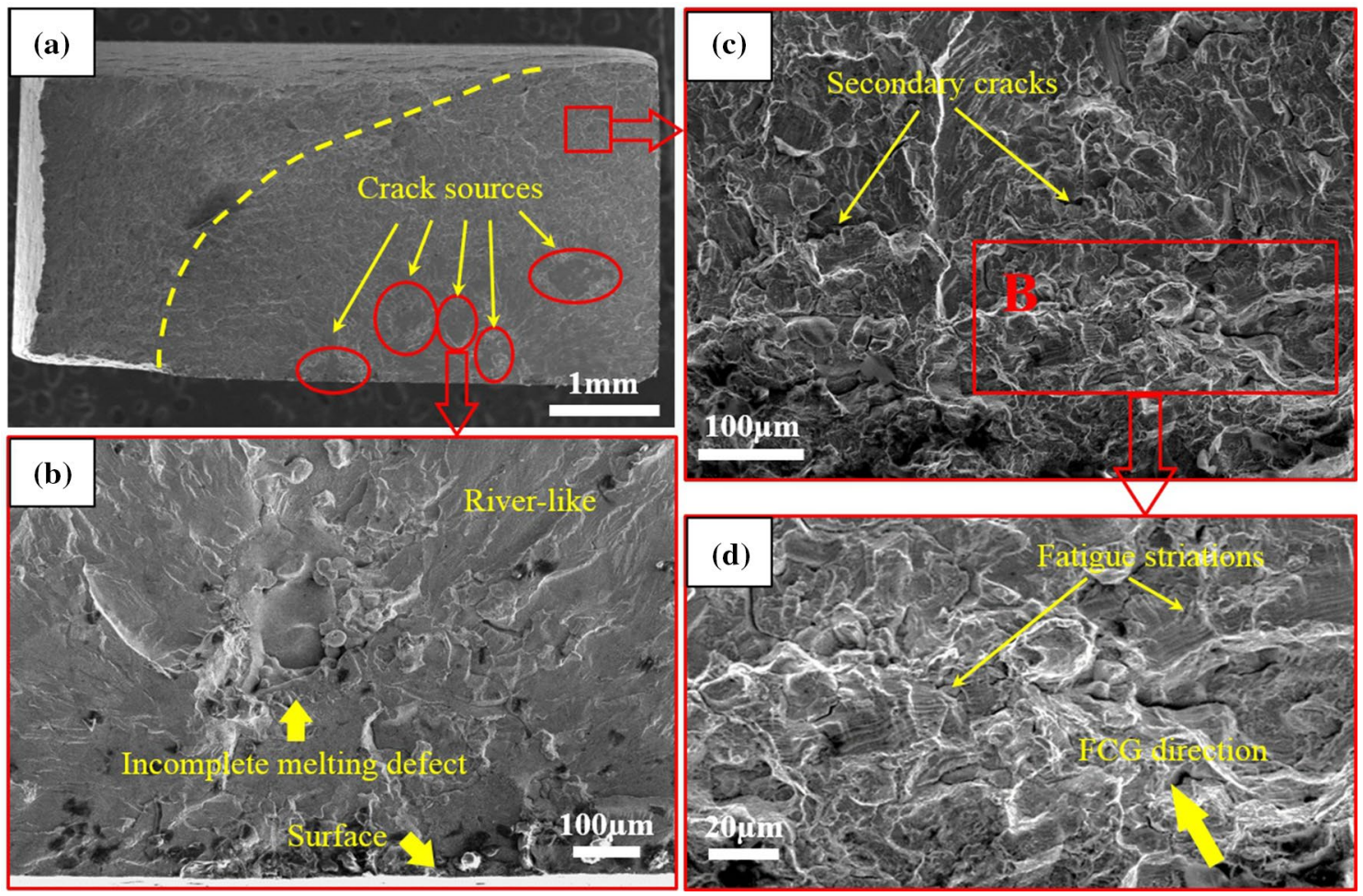

Fig. 12 Fracture surfaces of fatigue specimen $\mathrm{A}_{2}: \sigma_{\max }=200 \mathrm{MPa}, N_{\mathrm{f}}=213,495$
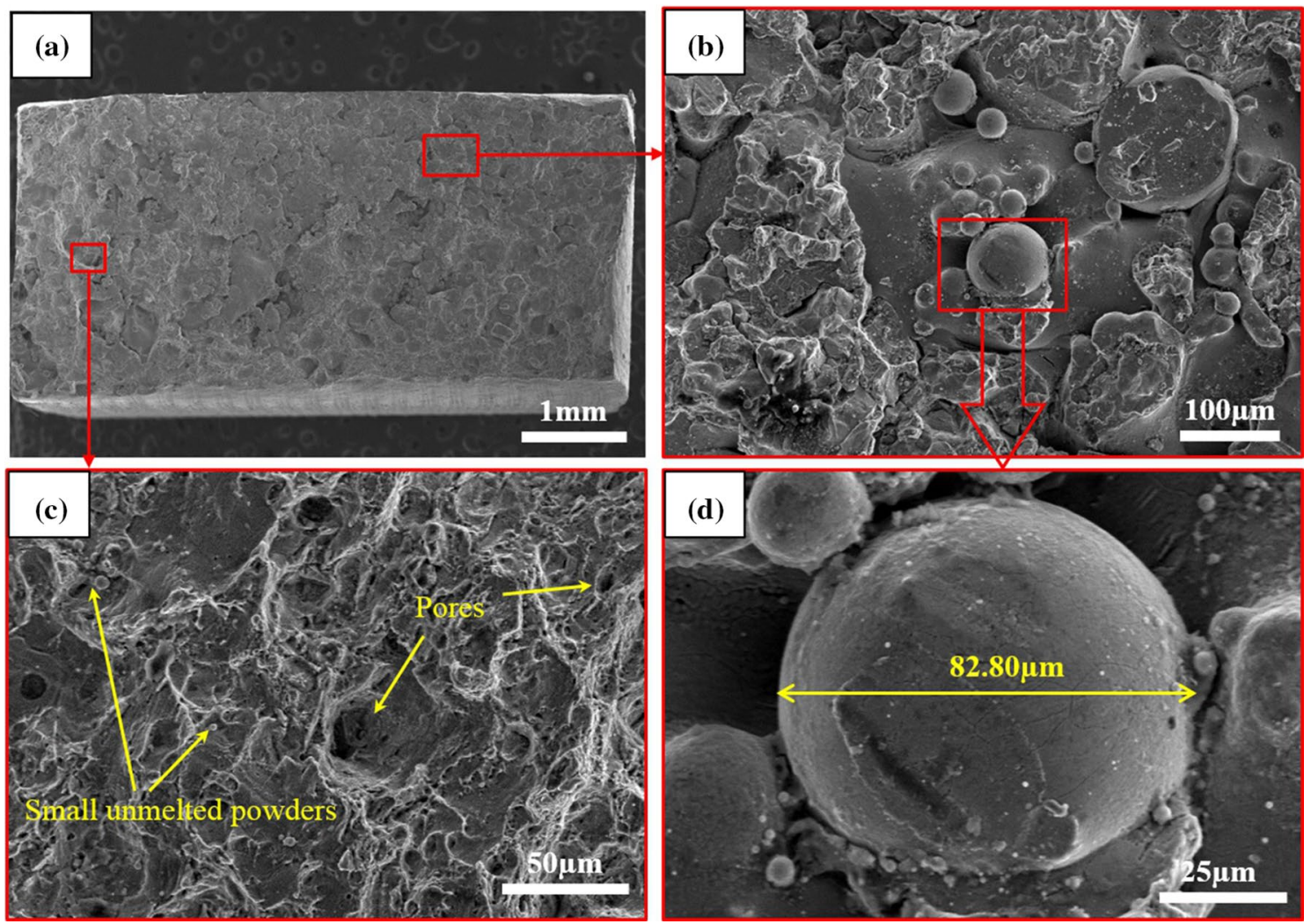

Fig. 13 Fracture surfaces of fatigue specimen $\mathrm{A}_{3}: \sigma_{\max }=200 \mathrm{MPa}, N_{\mathrm{f}}=4471$ 

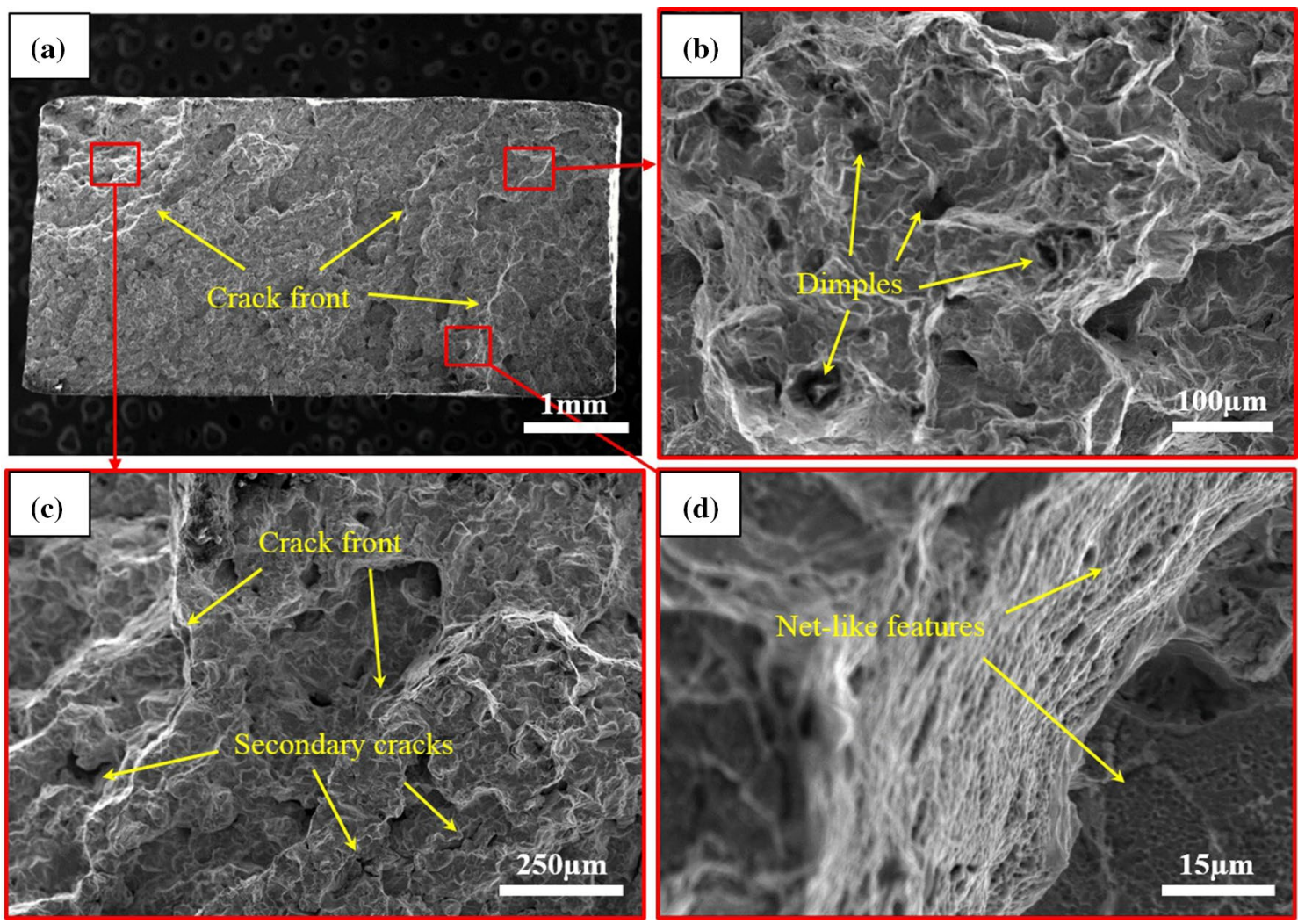

Fig. 14 Fracture surfaces of $\mathrm{D}_{1}: \sigma_{\max }=200 \mathrm{MPa}, N_{\mathrm{f}}=110$

two processes is presented in Fig. 15a, b. Both the yield and ultimate strength decreased with the increase in tested temperature. Both the yield and ultimate strength of SLM Inconel 625 appeared a slight decrease compared with the forged annealed bar, in which the decrease in yield strength is about $30 \%$, and the decrease in ultimate strength is about 20\%. As shown in Fig. 15c, when the temperature was below $540{ }^{\circ} \mathrm{C}$, the elongation rate of SLM Inconel 625 was slightly higher than that of the forged Inconel 625 . The ductility of most metals manufactured by the traditional procedures is increased at higher temperatures. Nevertheless, compared with the elongation (more than 50\%) of the conventionally forged Inconel 625 alloy [28], significant decrease in elongation (i.e., only $10 \%, 5 \%$ and $3 \%$ at the temperatures of $815{ }^{\circ} \mathrm{C}, 850{ }^{\circ} \mathrm{C}$ and $1000{ }^{\circ} \mathrm{C}$, respectively) was observed under the same conditions [32], indicating the poor ductility of SLM Inconel 625 . This poor ductility was further validated by the observations of fracture surface, where no obvious plastic deformation was detected on the microstructure level. On the one hand, a possible reason is that the grain uniformity of SLM Inconel 625 alloy is lower than that of the forged Inconel 625, resulting in uncoordinated
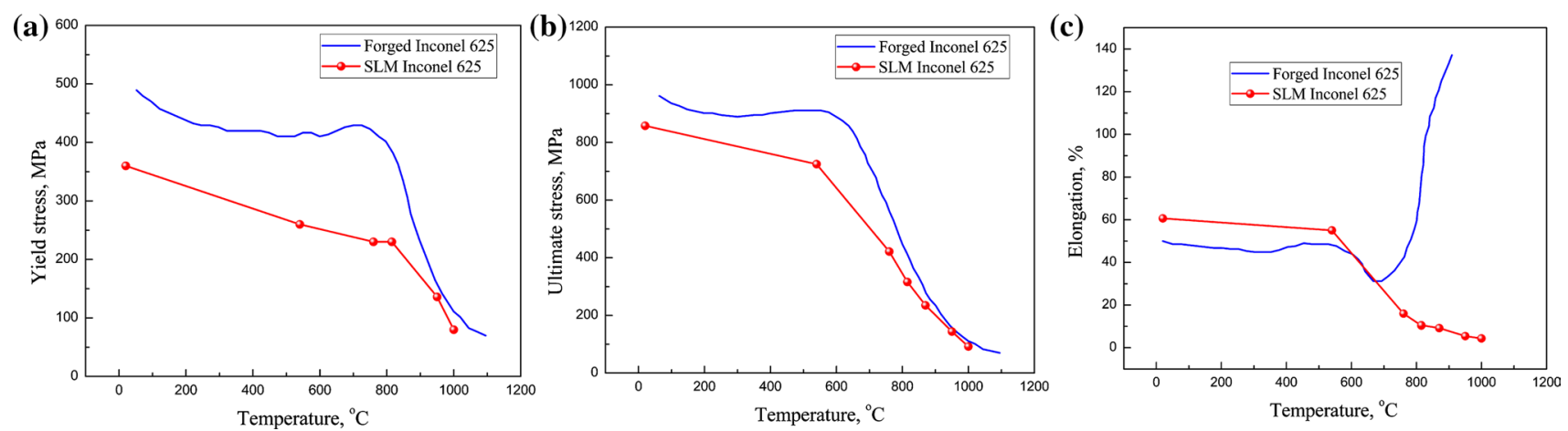

Fig. 15 a Yield, b ultimate stress, c elongation of annealed bar [28] and SLM Inconel 625 [32] at the fracture 
deformation during the loading process, and in turn rendering the grain boundaries more easily destroyed. On the other hand, the precipitation of carbide along the grain boundaries seriously affects the high-temperature mechanical behavior of the alloy [33]. The element distributions between and within the grains in the longitudinal surface of the specimens after tensile testing have been analyzed using the EDS method [32]. Compared with the element distribution at room temperature, accumulation of carbon was indentified across the grain boundaries at high temperatures, and carbide may precipitate as a continuous film at the grain boundaries, establishing a ground for crack formation. The formation of carbide precipitates at the grain boundaries also prevents sliding of the grain boundary. Thus, the formed carbides in the grain boundaries are closely associated with the reduced ductility of the SLM Inconel 625.

\subsubsection{Effect of Particle Melting Situation on the LCF Behavior}

During the SLM process, the line-by-line scanning of a highpower laser is essentially a non-equilibrium process [34]. Highly localized heats with considerable power act on the powders in a very short time, and the powders experience complex thermal cycles in a limited space with rapid heating up to several thousand $\mathrm{K} / \mathrm{s}$. A steep temperature gradient is generated from the local melted material to the part buckets. After the laser moves away, the material is solidified with a rapid cooling procedure. The quality of SLM-fabricated components is influenced by multiple parameters of the powder (quality and performance) and the process (i.e., laser power, scan speed and layer thickness). Although the mechanical performance of the material can be improved through the optimization of the SLM process and postprocess treatments, unfavorable microstructures and phases cannot be completely avoided [32]. In this study, all samples were manufactured in the same batch. However, as shown in Fig. 16, the totally melted, partially melted and unmelted particles in the samples (i.e., $A_{1}, A_{2}, A_{3}$ ) led to three distinct LCF damage mechanisms under the same maximum cyclic stress of $200 \mathrm{MPa}$. The longest fatigue life was observed in specimen $\mathrm{A}_{1}$, which had no partially melted or unmelted particles. The crack is normally initiated due to local plastic slip located in the right corner on the surface of the rectangular section specimen. The more undesirable situation was associated with specimen $\mathrm{A}_{2}$, which contained partially melted powder particles. Several crack initiation sites were found either on the surface or subsurface. The subsurface defects characterized by incompletely melted powder particles were critical positions of fatigue crack. This phenomenon is likely due to the insufficient energy to fuse the powders in the new layers. Although the embedded defects were as large as $100-200 \mu \mathrm{m}$, the bonding strength was still high.

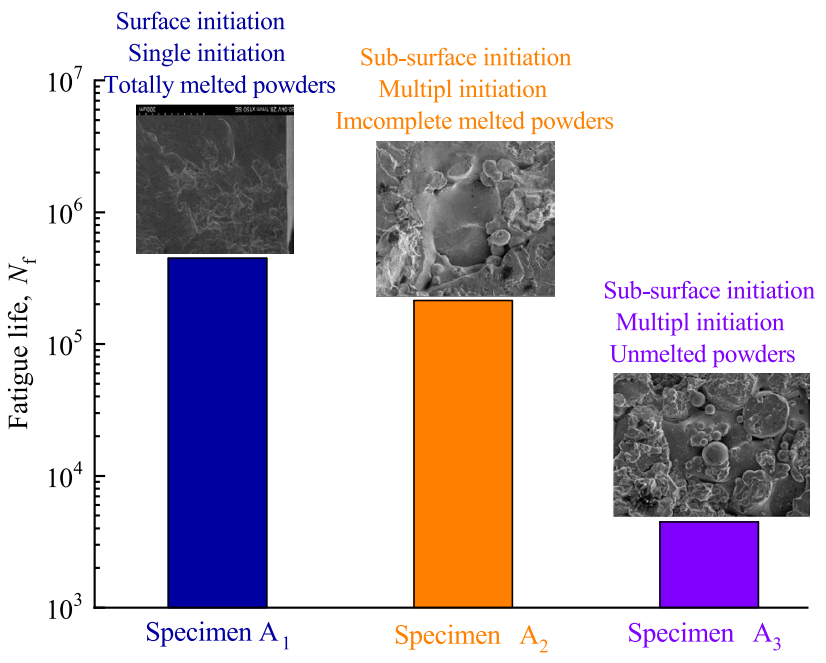

Fig. 16 Three different damage mechanisms controlling LCF failure of SLM 625 under the maximum stress of $200 \mathrm{MPa}$ at $815^{\circ} \mathrm{C}$

However, microcracks are apt to initiate due to the local stress concentration in the boundaries of the defects and different material properties, eventually reducing the half of the fatigue cycles to failure. Specimen $\mathrm{A}_{3}$ was in the most detrimental situation, as it contained a substantial amount of unmelted powder particles. The size of partially unmelted powders was significantly greater than the statistical average particle size of $12 \mu \mathrm{m}$. The normal laser energy was not high enough for complete melting of the powders with abnormally large sizes, leading to the formation of defects with large sizes. As a result of the complete loss of bounding force in the local regions, the large defects can be directly treated as cracks, which arisen from the first cycle. Thus, only two stages of fatigue occurred, i.e., crack growth and final fracture, resulting in only $2 \%$ of the normal fatigue life. Gong et al. [35] have reported similar findings that due to the lower-than-optimum energy density, unmelted powder defects are present in SLM Ti-6Al-4V, strongly affecting both tensile and fatigue properties. Liu et al. [36] also found that the unmelted powders represent a major source of crack initiation, and such defects would significantly decrease the fatigue life.

Meanwhile, in order to detect the potential defects in all specimens, nondestructive $\mathrm{X}$-ray testing was performed before the tensile and fatigue tests. The relative experimental parameters such as tube voltage, tube current, focal length, focus diameter and integral time were $150 \mathrm{kV}, 5 \mathrm{~mA}$, $900 \mathrm{~mm}, 0.4 \mathrm{~mm}$ and $400 \mathrm{~ms}$, respectively. Overall, except for specimen $\mathrm{A}_{3}$ as shown in Fig. 17, no significant defect could be identified in the other 11 specimens, demonstrating that the Inconel 625 components manufactured by SLM process had no inner primary cracks under the conditions of current process parameters. In specimen $\mathrm{A}_{3}$, the linearly 


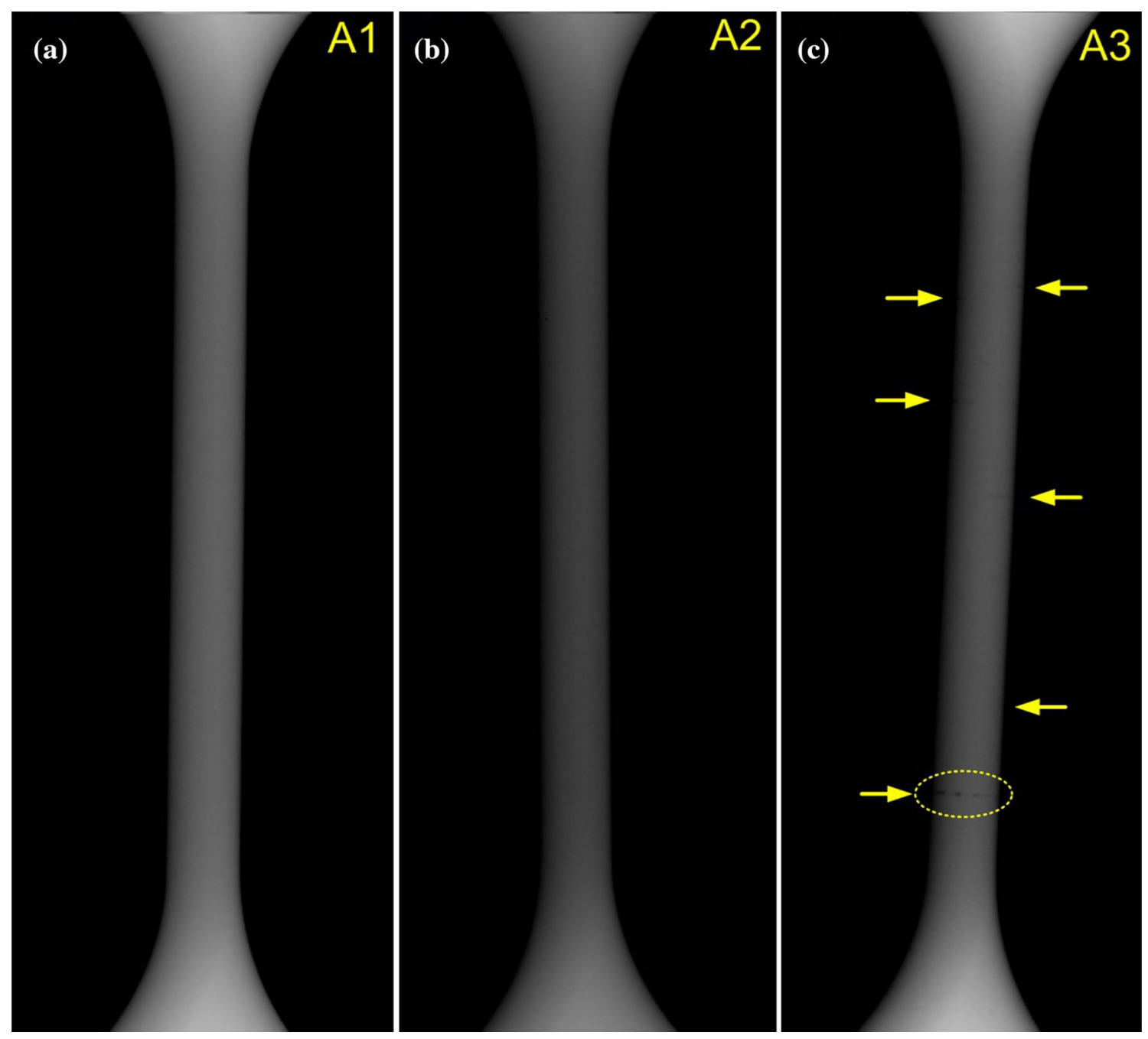

Fig. 17 Nondestructive X-ray testing results of specimens: a $A_{1}, \mathbf{b} A_{2}, \mathbf{c} A_{3}$

distributed defects are visible in multiple locations. In particular, the defects with large sizes are distributed along the line scanning direction of the test piece. To a certain extent, the linearly distributed defects vertical to the loading direction can be considered as linearly arranged microcracks, which contribute to severe deterioration of fatigue performance.

\subsubsection{Effect of Intergranular Cracking on the Elongation of LCF With and Without Dwell Time}

The SLM Inconel 625 exhibited poor ductility at $815{ }^{\circ} \mathrm{C}$ in this study, and related literature has also discovered the embrittlement of SLM Inconel 625 due to grain cracking under tensile loading at high temperatures [37]. The generation of carbides in the grain boundaries plays a critical role in the severely declined ductility properties of the SLM Inconel 625. According to the previous analysis, the elongation rate after pure $\mathrm{LCF}$ fracture $\left(\sigma_{\max }=300 \mathrm{MPa}\right)$ was about $18 \%$, which was significantly larger than that after tensile fracture. However, the elongation rate after CFI fracture $\left(\sigma_{\max }=200 \mathrm{MPa}\right)$ was about $11 \%$, which was similar to that after tensile fracture. The differences in elongation with and without dwell time in the LCF test may be attributed to the different roles of the intergranular cracking in the process of failure. Figure 18 shows the longitudinal section of the polished specimens under LCF and CFI, from which we can conclude that the microcracks were initiated in the grain boundary. Multiple opened microcracks readily formed in the grain boundaries that lied in the transverse direction of the CFI specimens, while few cracks were extended to a limited degree in the LCF specimens.

As shown in Fig. 18a-c, since the time during high stress interval was relatively short under pure LCF loading, the initiated microcracks in the grain boundaries grew to only $100 \mu \mathrm{m}$ before the failure. This means that the cracks 


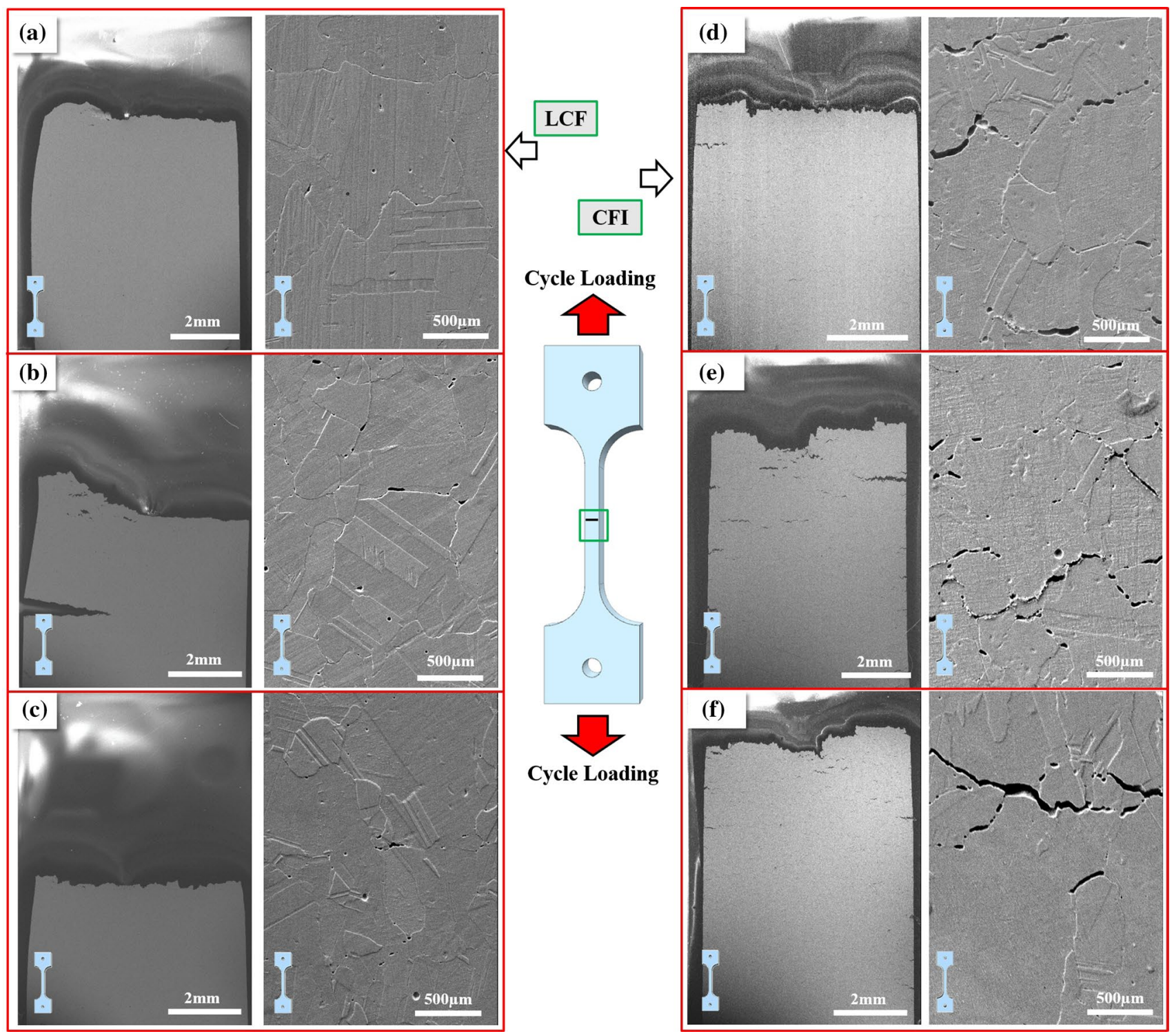

Fig. 18 SEM images of the longitudinal section of LCF and CFI specimens: a $A_{1}, \mathbf{b ~} B_{1}, \mathbf{c C}_{1}, \mathbf{d ~} \mathrm{D}_{1}, \mathbf{e ~} \mathrm{D}_{2}, \mathbf{f} \mathrm{D}_{3}$

originated mainly due to local plastic slip or expansion of nearby defects [38]. Therefore, new features existed in the embrittlement of SLM Inconel 625 alloy under pure LCF loadings due to grain cracking, and the improved elongation rate was about $18 \%$. As illustrated in Fig. $18 \mathrm{~d}-\mathrm{f}$, as the time in high stress interval was relatively long under the CFI loading with adequate dwell time, the accumulation of creep strain in one cycle was far greater than the plastic strain induced by the LCF damage. Hence, the microcracks initiated along the grain boundaries were further expanded and linked together to form long cracks. However, relative low ductility ( $10 \%$ elongation) was observed during the tensile tests, and a similar grain cracking mechanism was identified during CFI loading, leading to a similar elongation of $11 \%$ after the CFI fracture. Accordingly, the strain to creep failure and the fatigue life were remarkably low, and grain cracking was the main reason for the reduction in lifetime under creep-fatigue loading.

\section{Conclusions}

The effects of stress amplitude, dwell time and microstructure on LCF and CFI behaviors of Inconel 625 alloy manufactured by SLM were experimentally studied at $815^{\circ} \mathrm{C}$. The crack initiation and propagation mechanisms were investigated using OM and SEM. The key conclusions are summarized as follows: 
(1) The Inconel 625 alloy manufactured by SLM exhibited dramatic embrittlement in comparison with the forged alloy of the same composition at $815^{\circ} \mathrm{C}$. The cyclic life decreased substantially with the increased stress amplitude, and the introduction of dwell time was found to be especially detrimental. In addition, the increase in dwell time had no obvious effect on the fracture time and the elongation after fracture.

(2) For the pure LCF, the cracks were typically initiated on the surface of the specimen with completely melted powder particles, and the intergranular fracture mode dominated the fatigue failure process. With the increase in stress amplitude, the crack source increased, and the area of transient fracture expanded gradually. Due to the accumulation of creep damage, cracks in the CFI test were initiated along the grain boundaries and then joined together, leading to a significant decline in fatigue life.

(3) The unmelted and partially melted particles, which were generated due to the limitations of the SLM process, are the main reasons for the large dispersion of LCF life. When a large amount of incompletely melted powder particles are present in the sample, the cracks begin to initiate and expand rapidly, thus greatly reducing the cyclic life of the sample. Therefore, the relevant parameters of the powders are directly related to the strength and cyclic life of SLM Inconel 625.

Acknowledgements This research was financially supported by the National Natural Science Foundation of China (No. U1633113), the National Natural Science Foundation of China (No. NSFC51905249) and the Natural Science Foundation of Jiangxi Province (No. 20192BAB216020).

\section{References}

[1] N.J. Harrison, I. Todd, K. Mumtaz, Acta Mater. 94, 59 (2015)

[2] O. Fergani, F. Berto, T. Welo, S.Y. Liang, Fatigue Fract. Eng. Mater. Struct. 40, 971 (2017)

[3] D.Z. Wang, K.L. Li, C.F. Yu, J. Ma, W. Liu, Z.J. Shen, Acta Metall. Sin. (Engl. Lett.) 32, 127 (2019)

[4] X. Hu, Z. Xue, G. Zhao, J. Yun, D. Shi, X. Yang, Mater. Sci. Eng. A 745, 335 (2019)

[5] D.B. Witkin, D.N. Patel, G.E. Bean, Fatigue Fract. Eng. Mater. Struct. 42, 166 (2019)

[6] L.Z. Wang, W.H. Wei, Acta Metall. Sin. (Engl. Lett.) 31, 807 (2018)

[7] F. Zhang, L.E. Levine, A.J. Allen, M.R. Stoudt, G. Lindwall, E.A. Lass, M.E. Williams, Y. Idell, C.E. Campbell, Acta Mater. 152, $200(2018)$
[8] G.W. Ma, W. Li, J. Yang, Sci. China Ser. E 61, 475 (2018)

[9] Y.M. Arısoy, L.E. Criales, T. Özel, B. Lane, S. Moylan, A. Donmez, Int. J. Adv. Manuf. Technol. 90, 1393 (2017)

[10] D. Hu, Q. Ma, L. Shang, Y. Gao, R. Wang, Mater. Sci. Eng. A 670, 17 (2016)

[11] D. Hu, T. Wang, Q. Ma, X. Liu, L. Shang, D. Li, J. Pan, R. Wang, Int. J. Fatigue 118, 237 (2019)

[12] F. Caiazzo, V. Alfieri, G. Corrado, P. Argenio, Int. J. Adv. Manuf Technol. 93, 4023 (2017)

[13] X. Ma, J. Jiang, W. Zhang, H.J. Shi, J. Gu, Crystals 9, 312 (2019)

[14] H. Hack, R. Link, E. Knudsen, B. Baker, S. Olig, Addit. Manuf. 14, 105 (2017)

[15] K. Amato, J. Hernandez, L.E. Murr, E. Martinez, J. Mater. Sci. Res. 1, 167 (2012)

[16] M. Rombouts, G. Maes, M. Mertens, W. Hendrix, J. Laser Appl. 24, 2575 (2012)

[17] I. Koutiri, E. Pessard, P. Peyre, O. Amlou, T. De Terris, J. Mater. Process. Technol. 255, 536 (2018)

[18] J. Saarimäki, M. Lundberg, H. Brodin, J.J. Moverare, Mater. Sci. Eng. A 722, 30 (2018)

[19] R. Konečná, L. Kunz, G. Nicoletto, A. Bača, Int. J. Fatigue 92, 499 (2016)

[20] V. Prithivirajan, M.D. Sangid, Mater. Des. 150, 139 (2018)

[21] Y. Yamashita, T. Murakami, R. Mihara, M. Okada, Y. Murakami, Proced. Struct. Integr. 7, 11 (2017)

[22] R.D. Xu, Z.H. Jiao, H.C. Yu, Proced. Struct. Integr. 7, 84 (2017)

[23] M.E. Aydinöz, F. Brenne, M. Schaper, C. Schaak, W. Tillmann, J. Nellesen, T. Niendorf, Mater. Sci. Eng. A 669, 246 (2016)

[24] M.M. Kirka, D.A. Greeley, C. Hawkins, R.R. Dehoff, Int. J Fatigue 105, 235 (2017)

[25] S. Li, Q. Wei, Y. Shi, Z. Zhu, D. Zhang, J. Mater. Sci. Technol. 31, 946 (2015)

[26] A.S. Johnson, S. Shao, N. Shamsaei, S.M. Thompson, L. Bian, JOM 69, 597 (2017)

[27] Y. Ai, S.P. Zhu, D. Liao, J.A.F.O. Correia, C. Souto, A.M.P. De Jesus, B. Keshtegar, Int. J. Fatigue 126, 165 (2019)

[28] Special Metals Corporation, High Performance Alloys Literature (2013), http://www.specialmetals.com/tech-center/alloys.html

[29] K.F. Walker, Q. Liu, M. Brandt, Int. J. Fatigue 104, 302 (2017)

[30] D. Ren, S. Li, H. Wang, W. Hou, Y. Hao, W. Jin, R. Yang, R.D.K. Misra, L.E. Murr, J. Mater. Sci. Technol. 35, 285 (2019)

[31] S. Leuders, T. Lieneke, S. Lammers, T. Tröster, T. Niendorf, J. Mater. Res. 29, 1911 (2014)

[32] X.A. Hu, G.L. Zhao, F.C. Liu, W.X. Liu, Rare Met. (2019). https ://doi.org/10.1007/s12598-019-01321-3

[33] P. Liu, Z.-K. Chu, Y. Yuan, D.-H. Wang, C.-Y. Cui, G.-C. Hou, Y.-Z. Zhou, X.F. Sun, Acta Metall. Sin. (Engl. Lett.) 32, 517 (2019)

[34] D.D. Gu, W. Meiners, K. Wissenbach, R. Poprawe, Int. Mater. Rev. 57, 133 (2013)

[35] H. Gong, K. Rafi, H. Gu, G.D.J. Ram, T. Starr, B. Stucker, Mater. Des. 86, 545 (2015)

[36] Y.J. Liu, S.J. Li, H.L. Wang, W.T. Hou, Y.L. Hao, R. Yang, T.B. Sercombe, L.C. Zhang, Acta Mater. 113, 56 (2016)

[37] A. Kreitcberg, V. Brailovski, S. Turenne, Mater. Sci. Eng. A 700, 540 (2017)

[38] X. Ma, D. Wei, Q. Han, S. Rui, D. Su, W. Yang, Z. He, J. Xiao, Y. Wu, H.J. Shi, J. Mater. Eng. Perform. 28, 3332 (2019) 